\title{
The measurement system for thermographic research on characteristic of cooling selected radiators in conditions of free convection
}

\author{
Minkina Waldemar, Klecha Daniel \\ Czestochowa University of technology, Al. Armii Krajowej 17, PL 42-200 Czestochowa, Poland \\ minkina@el.pcz.czest.pl, daniel.klecha@gmail.com
}

\begin{abstract}
:
The aim of this paper is to discuss method to compare cooling parameter in selected radiators. In this purpose measurement system was created which can be used to generate identical temperature under four radiators in the same time and conditions. Readings from analog sensors and thermograms were used to compare which radiator has the lowest temperature at the beginning and at the end of the measurement. Paper describes method to compare radiators using measurements from sensors and thermograms which is supplement to the theoretical calculations. Literature positions discuss this method slightly. Method is given capabilities to analyze whole process of cooling and deduce additional conclusions.
\end{abstract}

Key words: thermography, radiators, natural convection, calculations with COMSOL Multiphysics ${ }^{\circledR}$ software

\section{Introduction}

Design of radiators is a very complex and important issue. Optimal shape of radiator comes to reduction in weight and size. It follows the reduction of material used in factories [1, 2 , $3,4,5,6]$.

During experiments and model research should be noted some basic restrictions. This publication is focusing on natural convection in a room. Real devices are closed in a cover which generates additional problems to be solved. In the literature there is many publications using forced convection which reduces size of radiator but generates noise.

\section{Measurement system}

Measurement system was created to heat four radiators in the same time and heat transfer conditions. User is able to change maximum temperature of the board. Range is between 30 and $115^{\circ} \mathrm{C}$. Thermostat is installed under the board to reach selected temperature and preserve it. Red diode is installed into measurement system to inform about power on of the heater. Heat bed MK3 from RepRap 3d printer was used to achieve regular temperature on the whole surface. Every radiator field has individual analog sensor to check temperature using measurements. Aluminum and copper were used as heat conductors because of their good performance. Differences between fields are lower than one ${ }^{\circ} \mathrm{C}$. Every field has the same size of the area - square with a side of $6 \mathrm{~cm}$.

LabVIEW software is used to read 5 analog sensors e.g. four sensors from fields and one sensor located in the center of the heat bed which is used by thermostat. Measurements are displayed in charts and saved to file for later comparison.

Maximum temperature is reached after $15-20$ minutes. Stabilization of the system is visible because of chart characteristic and short time when heater is turned on. When system is stable, radiators can be placed on the fields and start to cooling heat bed. Radiators shouldn't affect on each other because of additional space between them $(4.5 \mathrm{~cm})$.

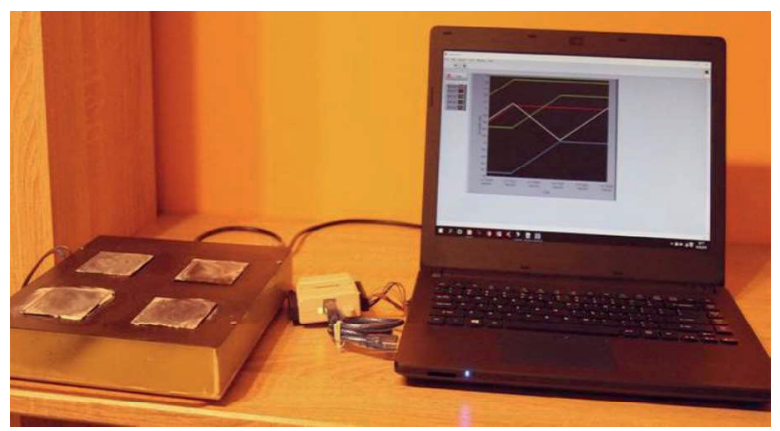

Fig. 1. Measurement system: heat bed, data acquisition device (NI USB-6008), laptop with data charts 


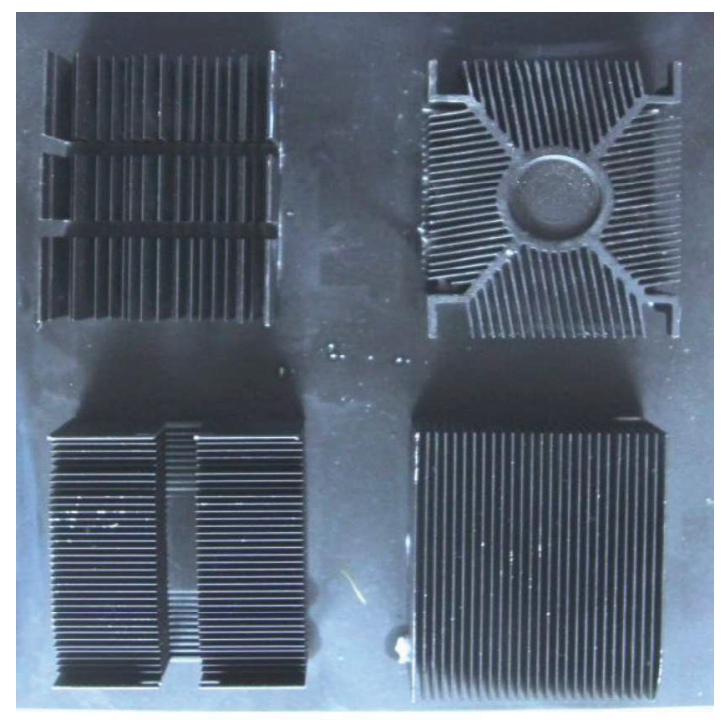

Fig. 2. Heatbed with installed four radiators

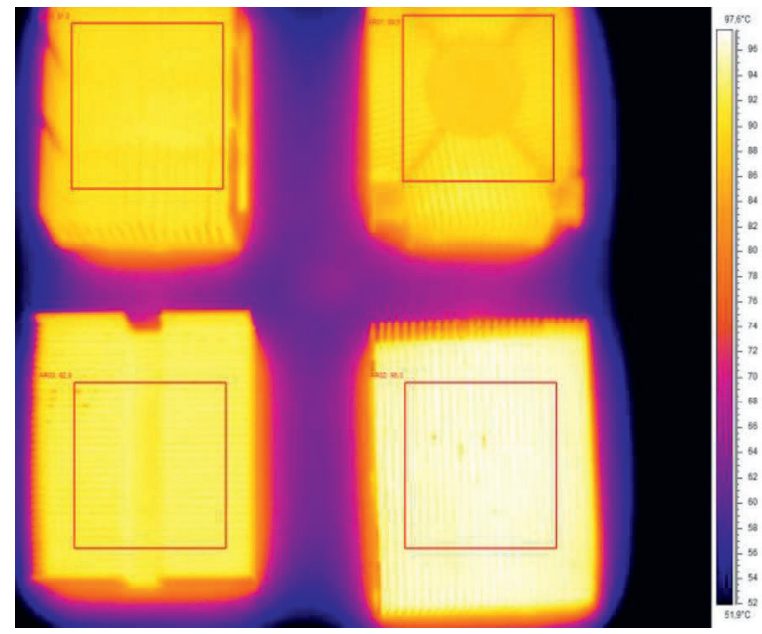

Fig. 3. Thermogram shows system with radiators

\section{Model research}

System from the experiment (fig. 2) was described in the model. COMSOL Multiphysics ${ }^{\circledR}$ program was used for this purpose [7]. The model research was performed on a high power computer in ACK CYFRONET AGH.

COMSOL Multiphysics ${ }^{\circledR}$ assembles and solves models using state-of-the-art numerical analysis methods. Several different methods are used in the add-on modules, including finite element analysis, the finite volume method, the boundary element method, and particle tracing methods, but the emphasis of COMSOL Multiphysics $^{\circledR}$ is on the finite element method. Many types of finite elements are available, and fully coupled elements are automatically generated by the software at the time of solving [7]. The basics of the theory of heat transfer used in this paper are presented in $[8,9,10$, 11].

The same geometry and materials was used as in the experiment. A result temperature was in the same range as in the experiment. The coolest radiator was the same as in the experiment. The hottest radiator was different.

Comparisons between results of two described methods are shown in table 2.

Tab. 1: Weights and surface areas of the radiators

\begin{tabular}{|c|c|c|}
\hline $\begin{array}{c}\text { The radiator } \\
\text { number }\end{array}$ & Weight, kg & $\begin{array}{c}\text { Surface } \\
\text { area, } \mathrm{m}^{2}\end{array}$ \\
\hline 1 & 0.327 & 0.134 \\
\hline 2 & 0.257 & 0.154 \\
\hline 3 & 0.289 & 0.156 \\
\hline 4 & 0.207 & 0.077 \\
\hline
\end{tabular}

Tab. 2: Temperature of the radiators

\begin{tabular}{|c|c|c|}
\hline $\begin{array}{c}\text { The } \\
\text { radiator } \\
\text { number }\end{array}$ & $\begin{array}{c}\text { Temperature } \\
\text { from the } \\
\text { experiment, }{ }^{\circ} \mathrm{C}\end{array}$ & $\begin{array}{c}\text { Temperature } \\
\text { from the model } \\
\text { research, }{ }^{\circ} \mathrm{C}\end{array}$ \\
\hline 1 & 89.5 & 75.8 \\
\hline 2 & 96.3 & 74.3 \\
\hline 3 & 92.8 & 74.2 \\
\hline 4 & 91.0 & 83.1 \\
\hline
\end{tabular}

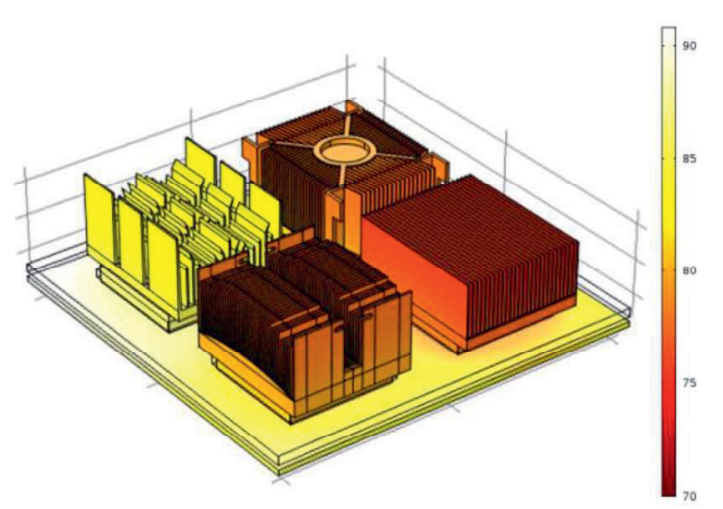

Fig. 4. $3 D$ thermogram calculated in program COMSOL Multiphysics ${ }^{\circledR}$

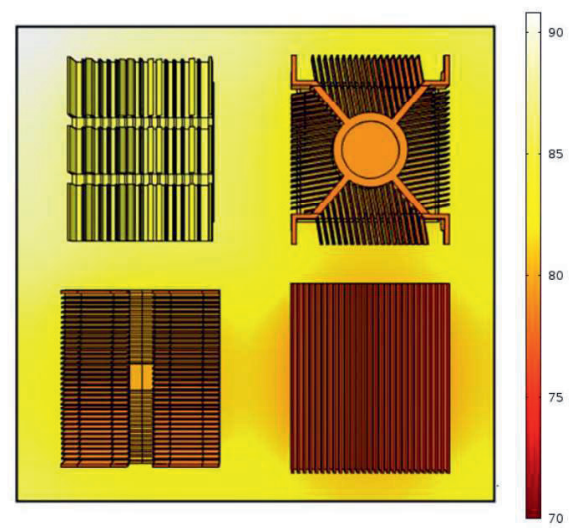

Fig. 5. $2 D$ thermogram calculated in program COMSOL Multiphysics ${ }^{\circledR}$ 


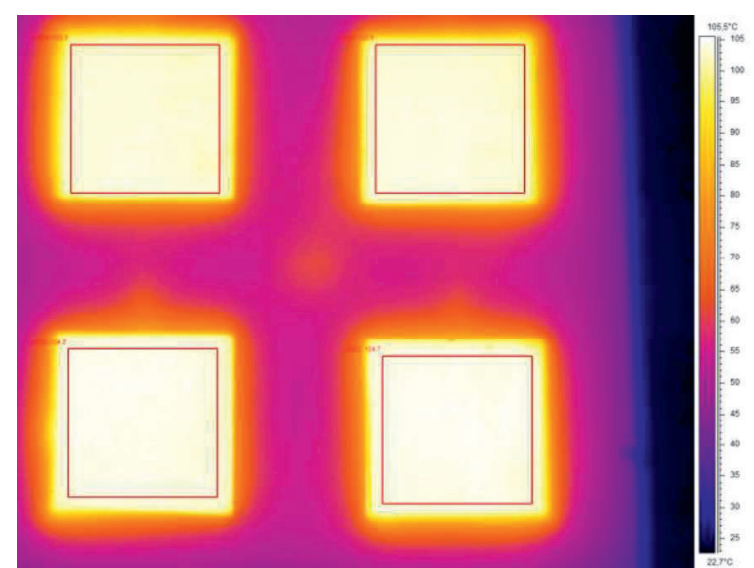

Fig. 6. Thermogram shows system without radiators when it's steady-state

\section{Research and conclusions}

Radiators are able to cool system faster than heather recover heather loses. This can be minimized using lower maximum temperature. The temperature drop is acceptable because conditions for all radiators are always the same.
Differences between temperatures of the radiators are noticeable and can be used to select the most performance radiator.

Result temperatures from the experiment and model research are in the same range. Differences could be generated because many small factors. Measurement system generates almost the same temperature on all of the fields. Differences are less than one degree during research without radiators. Model research could contain errors caused by approximations of the surface area. Research comes to conclusion that heat sinks can drain the same power regardless of the shape.

This is the initial research. Next stage of the work will be carried out extensive research with the other radiators which will contain different shapes, weights and surface areas. Research setting vertical orientation is predicted.

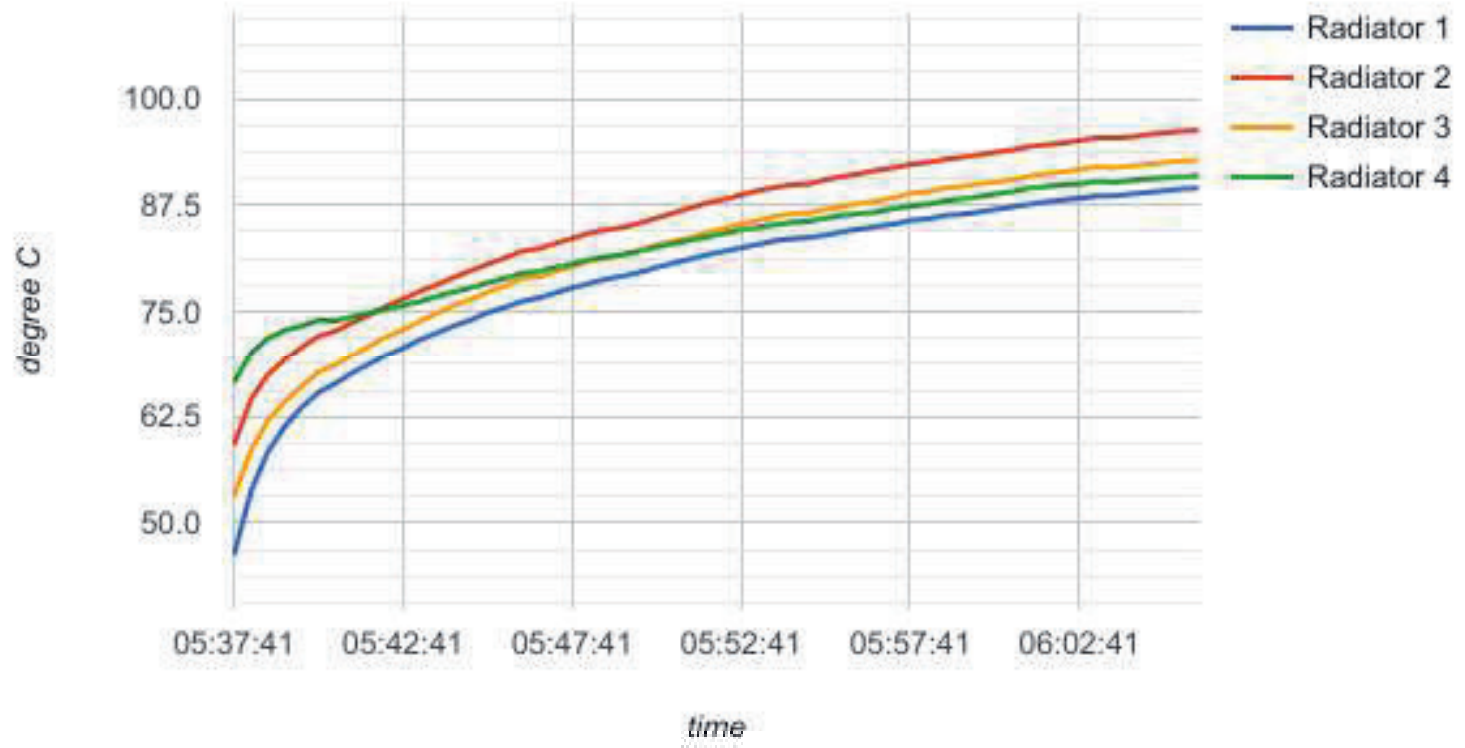

Fig. 7. Characteristic of the temperature of the radiators during time of the experiment 


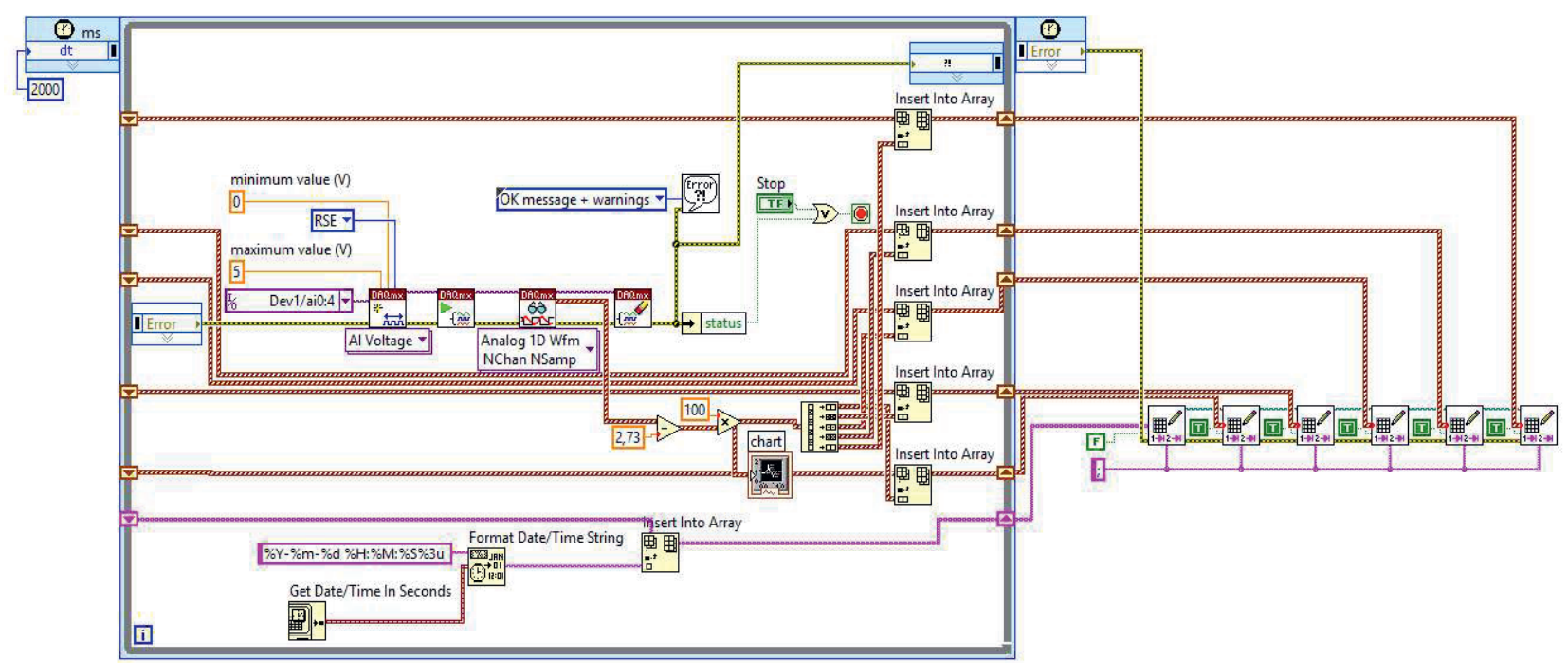

Fig. 8. Example of two-columns figure in LabVIEW software

\section{References}

[1] B. Więcek, M. Lis, S. Zwolenik, R. Danych, T. Wajman, Use of thermography in non-destructive testing and microelectronics, Pomiary Automatyka Kontrola (Measurement, Automation, Monitoring), 48 (2002) Nr 11, pp. 8-13 (in Polish)

[2] A. Bar-Cohen, M. lyengar, A.D. Kraus, Design of Optimum Plate-Fin Natural Convective Heat Sinks, Journal of Electronic Packaging 125(2) June 2003, DOI: 10.1115/1.1568361 (https://www.google.pl/?gws $\mathrm{rd}=\mathrm{ss} \mid \# \mathrm{q}=\% 22 \mathrm{Desig}$ n+of+Optimum+Plate-

Fin+Natural+Convective+Heat+Sinks $\% 22 \&^{*}$ )

[3] M. Nafar, M. Tavassoli, An Analysis for Optimization of Heat Transfer for Various Heat Sink Cross-section and Length, Australian Journal of Basic and Applied Sciences, 5(12): 1685-1682, $2011 \quad$ ISSN 1991-8178 (http://ajbasweb.com/old/ajbas/2011/December2011/1685-1692.pdf

[4] S.V. Kadbhane, D.D. Palande, Experimental Study of Natural Convective Heat Transfer from Vertical Rectangular Fin Array at Different Angle of Inclination, International Journal of Current Engineering and Technology E-ISSN 2277-4106, P-ISSN 2347-5161 (http://inpressco.com/wpcontent/uploads/2016/07/Paper71381-386.pdf

[5] V.S. Daund, A.A. Walunj, D.D. Palande, Review of natural convective heat transfer from rectangular vertical plate fins, International Journal of Advanced Technology in Engineering and Science, Volume No.02, Issue No. 07, July 2014

(http://ijates.com/images/short pdf/1406209133 P294-304.pdf)

[6] D. Das, A. Dwivedi, S. Gupta, Optimum Design Parameters for Heat Transfer from Triangular Fin Array within a Rectangular Enclosure, Asian Journal of Engineering and Applied Technology, ISSN 2249-068X Vol. 2 No. 2, 2013, pp. 47-51 (http://www.trp.org.in/wp-

content/uploads/2015/11/AJEAT-vol.2-No.2-JulyDec-2013-pp.47-51.pdf)

[7] Introduction to COMSOL Multiphysics ${ }^{\circledR}$ Users Guide, (c) 1998-2015 COMSOL: http://people.ee.ethz.ch/ fieldcom/ppscomsol/documents/User\%20Guide/COMSOLMult iphysicsUsersGuide.pdf

[8] G.N. Dulniew, Heat transfer in electrical devices and their elements, WN-T Publisher, Warsaw 1967 (in Polish)

[9] J.P. Holman, Heat Transfer, McGraw-Hill, New York, 10th Ed 2009, ISBN 978-0-07-352936-3

[10] K. Wark, Thermodynamics, McGraw-Hill Book Company, New York, 1988, ISBN 0-07-068286-0

[11] Minkina W., Dudzik S, Infrared thermography errors and uncertainties, John Wiley \& Sons Ltd, Chichester 2009, ISBN 978-0-470-74718-6, OnlineBooks ${ }^{\text {TM }}$ ISBN 978-0-470-68223-4 